\section{(C) OPEN ACCESS}

\title{
How to improve the assessment of the impact of occupational diseases at a national level? The Netherlands as an example
}

\author{
Henk F van der Molen, Carel TJ Hulshof, P Paul FM Kuijer
}

Amsterdam UMC, University of Amsterdam, Department: Coronel Institute of Occupational Health, Netherlands Center for Occupational Diseases, Amsterdam Public Health research institute, Amsterdam, The Netherlands

\section{Correspondence to}

Dr Henk F van der Molen, Amsterdam UMC, University of Amsterdam, Department: Coronel Institute of Occupational Health, Netherlands Center for Occupational Diseases, Amsterdam Public Health research institute, Amsterdam 1100 DD, The Netherlands; h.f.vandermolen@amc.nl

Received 26 July 2018 Revised 11 September 2018 Accepted 23 September 2018 Published Online First 8 October 2018

\section{ABSTRACT \\ Objective To explore the impact of occupational diseases (ODs) through estimations of population attributable fractions (PAFs) in a national context.} Methods PAFs were calculated for eight prevalent ODs using existing data on the prevalence of exposure to risk factors at work and the strength of their association with diseases based on systematic reviews. Six systematic reviews with meta-analyses and two overview papers were selected. All addressed the relationship between occupational exposure to work-related risk factors for these eight prevalent ODs. Prevalence figures for exposure to work-related risk factors were retrieved from the Dutch National Working Conditions Survey (NWCS) based on self-reports by approximately 40000 workers. The specific risk factors retrieved from the reviews were matched with the available and dichotomised selfreported exposure items from the NWCS by two authors. Results The eight frequently reported ODs among the Dutch working population revealed PAFs varying between $3 \%$ and $25 \%$. Lateral epicondylitis and distress/ burnout had the highest attributable fractions, with percentages of $25 \%$ and $18 \%$, respectively. For knee osteoarthritis (13\%), shoulder soft tissue disorders (10\%) and non-specific low back pain (10\%) approximately 1 in 10 cases were attributable to work. PAFs for irritant contact dermatitis, noise-induced hearing loss and chronic obstructive pulmonary disease were 15\%,6\% and $3 \%$, respectively.

Conclusion Data from systematic reviews and selfreported data on exposure provide opportunities to estimate the impact of ODs. For the Netherlands, they revealed substantial and varying attributions of work for prevalent diseases.

\section{INTRODUCTION}

Data on occupational diseases (ODs) are essential for government bodies, employers, trade unions, social security institutions, occupational health and safety professionals and other stakeholders to fulfil their ambition and obligation to prevent and control work-related diseases. ${ }^{1}$ In the Netherlands, as in other countries, ODs are under-reported because their registration depends on the behaviour of occupational physicians and on the case definitions for ODs. The reporting of ODs by occupational physicians is hindered by its perceived lack of usefulness, lack of urgency, the complexity of assessment and concern about liability issues. ${ }^{2}$ Worldwide, a lack of clear and standardised case

\section{Key messages}

What is already known about this subject?

- Registries for occupational diseases (ODs) depend on the behaviour of occupational physicians and case definitions for ODs. Alternative approaches could enhance insight into the impact of ODs in a national context.

What are the new findings?

- Simple estimates of population attributable fractions (PAF) were retrieved from existing data on work-related exposure and the strength of the association between diseases and work-related risk factors. These PAFs enhance epidemiological knowledge about the impact of ODs in a national context.

How might this impact on policy or clinical practice in the foreseeable future?

- Knowledge of PAFs of prevalent ODs might stimulate the use of work-related exposure reduction as a short term and easily obtainable proxy for the prevention of ODs.

and exposure definitions, ${ }^{3}$ as well as the absence of standardised eligibility criteria for OD recognition between countries, ${ }^{45}$ may also hamper the gathering of reliable data on ODs.

To stimulate recognition, ensure consistency in the case definitions of ODs and contribute to the prevention of work-related diseases in occupationally exposed groups, international criteria documents have been developed by the WHO, the International Labour Organisation and the European Union. ${ }^{67}$ In addition, national OD registration or diagnostic guidelines have been developed and disseminated. ${ }^{8}$ To increase the quality and compliance in the reporting of ODs, the development and use of these guidelines could indeed be promising with respect to retrieving more reliable estimates of OD within and between countries.

An additional approach to retrieving more reliable OD estimates within and between countries involves estimates of population attributable fractions (PAFs), based on high-quality systematic reviews regarding work-related risk factors for clinically assessed diseases, preferably with meta-analyses, and estimates of the prevalence of exposure to work-related risk factors in the workplace. In reply 
to a government request to obtain more reliable estimates of the burden of ODs, this approach was explored in a national context in the Netherlands.

\section{METHODS}

Based on systematic reviews, PAFs were estimated for eight prevalent ODs using existing data on the prevalence of exposure to risk factors at work and the strength of their association with the disease. PAFs were calculated according existing formulas ${ }^{9}$ : (proportion of workers exposed to risk factor) $\times$ (attributable proportion in the exposed $)=P_{e}\left(R_{e}-1\right) /\left[1+P_{e}\left(R_{e}-1\right)\right]$. The $\mathrm{PAF}$ indicates the proportion of disease that would not occur in a working population if the exposure to a risk factor at work was eliminated. The attributable risk in the working population depends on the prevalence of exposure to the risk factor and the strength of its association with the disease.

Six systematic reviews with meta-analyses were identified that addressed the relationship between occupational exposure to work-related risk factors for six prevalent ODs: lateral epicondylitis, ${ }^{10}$ knee osteoarthritis, ${ }^{11}$ specific soft tissue disorders of the shoulder, ${ }^{12}$ non-specific low back pain, ${ }^{13}$ distress/burnout ${ }^{14}$ and chronic obstructive pulmonary disease (COPD). ${ }^{15}$ The systematic reviews selected revealed epidemiological evidence of a prospective association between exposure to work-related physical risk factors and the four musculoskeletal disorders (summary ORs: 1.3-2.6), chemicals and COPD (summary OR: 1.4), and psychosocial factors and mental disorders (summary ORs: 1.3-2.0).

For lateral epicondylitis, hand force, repetitive movement, hand-arm vibration and elbow load (combined physical exposure) were identified as risk factors at work. For knee osteoarthritis, kneeling or squatting, lifting and climbing were identified as risk factors. For specific soft tissue disorders of the shoulder, arm-elevation, hand force, hand-arm vibration and shoulder load (combined physical exposure) were identified as risk factors. For non-specific low back pain, manual material handling, bending and twisting of the trunk and whole body vibration were identified as risk factors. For distress/burnout, job demands, emotional demands, low decision authority, effort-reward imbalance, low co-worker support, low supervisor support, low procedural justice and low relational justice were identified as risk factors. Exposure to vapours, gases, dust or fumes was identified as a risk factor for COPD. In addition, overview papers were used for hearing $\operatorname{loss}^{16}$ and irritant contact dermatitis, ${ }^{17}$ with exposure to noise and wet work identified as occupational risk factors, respectively. The overview papers reported associations between exposure to wet work and irritant contact dermatitis $(\mathrm{OR}=2.1)$ and exposure to noise and noise-induced hearing loss $(\mathrm{OR}=1.9)$.

Prevalence figures for exposure to work-related risk factors were retrieved from the National Working Conditions Survey (NWCS), ${ }^{18}$ executed in 2017 using a representative sample of the Dutch working population. Data on exposure were based on self-report by workers $(n=39986-41859)$, usually on a one-item question with a three-point or four-point answer scale such as: 'Do you exert force during work?' ('yes, regularly', 'yes, sometimes', 'no') or 'Is your skin exposed to wet work?' ('never', 'sometimes', 'often', 'always'). As a best estimate, the specific risk factors retrieved from the systematic reviews were matched with the available and self-reported exposure items from the NWCS ${ }^{18}$ by two authors.

Subsequently, risk factors were categorised and exposure dichotomised as follows: physical risk factors in terms of force (combined physical exposure wrist and elbow: lateral epicondylitis; hand force: specific soft tissue shoulder disorder; lifting:
Table 1 Estimated population attributable fractions of diseases due to exposure to work-related risk factors in the Netherlands

\begin{tabular}{|c|c|c|c|c|}
\hline \multirow{2}{*}{$\begin{array}{l}\text { International Classification } \\
\text { of Diseases-10 }\end{array}$} & \multirow{2}{*}{$\begin{array}{l}\text { Prevalence } \\
\text { Risk factors (\%) }\end{array}$} & \multicolumn{2}{|c|}{ Risk ratio } & \multirow{2}{*}{$\begin{array}{l}\text { PAF } \\
\%\end{array}$} \\
\hline & & OR & $95 \% \mathrm{Cl}$ & \\
\hline \multicolumn{5}{|l|}{ Musculoskeletal } \\
\hline \multicolumn{5}{|l|}{ Lateral epicondylitis } \\
\hline Force & 21.0 & 2.6 & 1.9 to 3.5 & 25 \\
\hline Posture & 10.8 & 2.6 & 1.9 to 3.5 & 15 \\
\hline \multicolumn{5}{|l|}{ Knee osteoarthritis } \\
\hline Force & 21.0 & 1.7 & 1.4 to 2.0 & 13 \\
\hline Posture & 10.8 & 1.7 & 1.4 to 2.1 & 7 \\
\hline \multicolumn{5}{|c|}{ Shoulder soft tissue disorders } \\
\hline Force & 21.0 & 1.5 & 1.3 to 1.9 & 10 \\
\hline Posture & 10.8 & 1.9 & 1.5 to 2.5 & 9 \\
\hline \multicolumn{5}{|l|}{ Non-specific low back pain } \\
\hline Force & 21.0 & 1.5 & 1.3 to 1.7 & 10 \\
\hline Posture & 10.8 & 1.7 & 1.4 to 2.0 & 7 \\
\hline \multicolumn{5}{|l|}{ Mental } \\
\hline \multicolumn{5}{|l|}{ Distress/Burnout } \\
\hline Work quantity & 46.2 & 1.5 & 1.4 to 1.6 & 18 \\
\hline Emotional demanding & 12.9 & 1.6 & 1.4 to 1.9 & 7 \\
\hline Low decision authority & 12.7 & 1.3 & 1.2 to 1.5 & 4 \\
\hline Low support manager & 15.5 & 1.3 & 1.2 to 1.4 & 4 \\
\hline Low support colleague & 4.2 & 1.3 & 1.2 to 1.4 & 1 \\
\hline \multicolumn{5}{|l|}{ Dermal } \\
\hline \multicolumn{5}{|l|}{ Irritant contact dermatitis } \\
\hline Wet work & 15.8 & 2.1 & 1.4 to 3.0 & 15 \\
\hline \multicolumn{5}{|l|}{ Auditive } \\
\hline \multicolumn{5}{|l|}{ Hearing loss } \\
\hline Noise & 7.5 & 1.9 & - & 6 \\
\hline \multicolumn{5}{|l|}{ Respiratory } \\
\hline \multicolumn{5}{|l|}{ COPD } \\
\hline Inhaling substances & 8.1 & 1.4 & 1.2 to 1.7 & 3 \\
\hline
\end{tabular}

COPD, chronic obstructive pulmonary disease.

knee osteoarthritis; manual material handling: non-specific low back pain), posture (combined physical exposure wrist and elbow: lateral epicondylitis; arm elevation: specific soft tissue shoulder disorder; kneeling or squatting: knee osteoarthritis; bending and twisting: non-specific low back pain) and noise ('yes, regularly'). Psychosocial risk factors in terms of job demands, decision authority, emotional demands ('often' or 'always'); social support from manager and social support from colleagues (mean $\leq 2.5$ on a two-item scale with four answer categories); chemical risk factors such as inhaling substances ('often' or 'always'); and dermal exposure to wet work ('often' or 'always'). The prevalence of work-related risk factors varied between $4 \%$ and $46 \%$ (see table 1 ).

\section{RESULTS}

The eight frequently reported ODs among the Dutch working population revealed PAFs varying between $3 \%$ and 25\% (table 1). Lateral epicondylitis and distress/burnout showed the highest attributable fractions, with percentages of $25 \%$ and $18 \%$, respectively. For irritant contact dermatitis (15\%), knee osteoarthritis (13\%), shoulder soft tissue disorders (10\%) and non-specific low back pain (10\%), approximately 1 in $7-10$ cases were attributable to work. Of the diseases selected, the lowest PAFs were for noise-induced hearing loss (6\%) and COPD (3\%). 


\section{DISCUSSION}

The results show that a fairly simple approach may increase insight into the impact of ODs independently of national social security regulations if PAFs can accurately be calculated. If so, these PAFs could also be calculated for various of industry sectors and jobs when valid and reliable estimates of risk factors are available, thereby providing data to employers, workers and policy-makers about the industrial sectors and jobs at risk. This might increase the sense of urgency for the prevention of ODs.

Limitations of this explorative study encompass the self-reported wide exposure categories in the survey ${ }^{18}$ and the lack of knowledge about minimum exposure categories for different ODs. Furthermore, often knowledge was lacking about health effects due to combined exposures, for example, force and posture. Or, as for lateral epicondylitis, the effect of combined physical exposure on health is known, but the prevalence of self-reported combined exposures was unknown, therefore the PAF could vary up to $25 \%$.

Consequently, the accuracy of the calculated PAFs is hampered by the used data of exposure categories, the quality of estimated associations between work-related risk factors and their corresponding diseases, and exposure that is often not measured in similar ways in the survey as in the systematic reviews. Also, PAFs can be too optimistic in estimating the potential for prevention. ${ }^{9}$ Therefore, intervention studies are needed to assess effectiveness in daily work.

However, the potential effect of preventive actions on work-related exposure in terms of the occurrence of ODs and their medical and productivity costs can still be explored. For example, in the Netherlands, the annual incidence of knee osteoarthritis among men and women in the working age bracket of 45-64 years, as assessed by family physicians in 2012, was 9 and 17 per 1000 patient years. Based on the data in table 1 , at least $7 \%$ of these cases seem preventable. Given that the Dutch working population in this age category is equivalent to approximately 2.0 million men and 1.6 million women, this would imply a preventable number of approximately 3200 cases annually, as a conservative estimate. The costs per month for each Dutch worker with knee osteoarthritis is €871: medical costs €148 $(17 \%)$ and productivity loss $€ 723(83 \%) .{ }^{19}$ Based on these data, the annual preventable costs can be estimated to be $€ 5.7$ million for care and $€ 27.8$ million in productivity loss.

Finally, the presented approach may encourage more close international collaboration ${ }^{20}$ regarding exposure assessments on standardised cut-off points for evidence-based risk factors; for example, in relation to daily exposure to hand-arm elevation $\geq 60^{\circ} \geq 1 \mathrm{hr} / \mathrm{day}$ in the case of work-related shoulder soft tissue disorders, or daily exposure to $86 \mathrm{~dB}(\mathrm{~A})$ over 10 years, for noise-induced hearing loss. The use of consensus-based international exposure criteria as outcome measures in intervention studies might also stimulate prevention of ODs, rather than waiting for the actual occurrence of ODs.

Correction notice This article has been amended since it first published. It has been made open access.

Contributors HFvdM: conceived and designed this short report, interpreted the data, and drafted this short report. All authors were involved in the conception of this study, made critical revisions and approved the final manuscript.
Funding This work was supported by the Dutch Ministry of Social Affairs and Employment, grant number 22085

Competing interests None declared.

Provenance and peer review Not commissioned; externally peer reviewed.

Open access This is an open access article distributed in accordance with the Creative Commons Attribution Non Commercial (CC BY-NC 4.0) license, which permits others to distribute, remix, adapt, build upon this work non-commercially, and license their derivative works on different terms, provided the original work is properly cited, appropriate credit is given, any changes made indicated, and the use is non-commercial. See: http://creativecommons.org/licenses/by-nc/4.0/.

\section{REFERENCES}

1 Zhang M. National System for Recording and Notification of Occupational Diseases: Practical guide. Geneva: International Labour Office, 2013

2 van der Molen HF, Omvlee L, Brand T, et al. Perceived barriers and facilitators in the assessment of occupational diseases. Occup Med 2018;57.

3 Turner MC, Mehlum IS. Greater coordination and harmonisation of European occupational cohorts is needed. Occup Environ Med 2018:75:475-6.

4 Van der Molen HF, Violante FS, Madan I, et al. Comparison of diagnostic criteria for occupational upper extremity disorders between countries. Occup Environ Med 2018;75(Suppl 2):A1-A650:254

5 Hulshof CTJ, van der Laan G, Braam ITJ, et al. The fate of mrs robinson: Criteria for recognition of whole-body vibration injury as an occupational disease. J Sound Vib 2002;253:185-94.

6 World Health Organization. Occupational and work-related diseases. http://www. who.int/occupational_health/activities/occupational_work_diseases/en/ (accessed 01 Feb 2018)

7 Mandic-Rajcevic S, Rubino FM, Colosio C. ILO Diagnostic and exposure criteria for occupational diseases. final meeting of the working group and public conference, University of Milan, Italy, 26th - 30th June 2017. Med Health Work Life 2017;108:493-4.. 2017;108:493-4.

8 Boschman JS, Brand T, Frings-Dresen MH, et al. Improving the assessment of occupational diseases by occupational physicians. Occup Med 2017;67:13-19.

9 Poole C. A history of the population attributable fraction and related measures. Ann Epidemiol 2015;25:147-54.

10 Descatha A, Albo F, Leclerc A, et al. Lateral epicondylitis and physical exposure at work? a review of prospective studies and meta-analysis. Arthritis Care Res 2016;68:1681-7

11 Verbeek J, Mischke C, Robinson R, et al. Occupational exposure to knee loading and the risk of osteoarthritis of the knee: a systematic review and a dose-response metaanalysis. Saf Health Work 2017;8:130-42.

12 van der Molen HF, Foresti C, Daams JG, et al. Work-related risk factors for specific shoulder disorders: a systematic review and meta-analysis. Occup Environ Med 2017;74:745-55.

13 Lötters F, Burdorf A, Kuiper J, et al. Model for the work-relatedness of low-back pain. Scand J Work Environ Health 2003;29:431-40.

14 De Groene GJ, Nieuwenhuijsen K, Frings-Dresen MHW, et al. 345 Which psychosocial risk factors at work contribute to the onset of stress-related disorders? a systematic review and meta-analysis. Occup Environ Med 2018;75:A583 .2-A583:1644.

15 Ryu JY, Sunwoo YE, Lee SY, et al. Chronic Obstructive Pulmonary Disease (COPD) and Vapors, Gases, Dusts, or Fumes (VGDF): A Meta-analysis. COPD 2015;12:374-80.

16 Nelson DI, Nelson RY, Concha-Barrientos M, et al. The global burden of occupational noise-induced hearing loss. Am J Ind Med 2005;48:446-58.

17 Diepgen T. Epidemiology and job-related problems for the eczema patient. Acta Derm Venereol 2005;215:41-4.

18 Hooftman WE, Mars GMJ, Janssen B, et al, 2017. National working conditions survey http://www.monitorarbeid.tno.nl/dynamics/modules/SFIL0100/view.php?fil_Id=229 (accessed 25 Jun 2018).

19 Hermans J, Koopmanschap MA, Bierma-Zeinstra SM, et al. Productivity costs and medical costs among working patients with knee osteoarthritis. Arthritis Care Res 2012;64:853-61.

20 Hulshof CTJ, et al. Protocol for systematic reviews of exposure to occupational ergonomic risk factors and of the effect of exposure to occupational ergonomic risk factors on osteoarthritis of hip or knee and selected other musculoskeletal diseases. Environ Int, conditionally accepted. 